\title{
A DIMENSÃO PULSIONAL DO SENSÍVEL: ELABORAÇÕES ACERCA DA PERCEPÇÃO EM RENAUD BARBARAS'
}

\author{
Danilo Saretta Verissimo* \\ Departamento de Psicologia Evolutiva, Social e Escolar, \\ Faculdade de Ciências e Letras de Assis, Universidade Estadual Paulista - UNESP, \\ Assis, SP, Brasil
}

\begin{abstract}
Resumo: Neste artigo, analisamos o trabalho teórico realizado por Renaud Barbaras a partir de seu propósito de destacar e desenvolver a potencialidade da teoria husserliana da percepção, fundamentada na doutrina de doação perceptiva por perfis. Centramonos principalmente em sua obra intitulada O desejo e a distância: introdução a uma fenomenologia da percepção. Destacamos a descrição, operada pelo autor, do movimento vital como desejo e a caracterização do sujeito da percepção como vivente. Sob esta condição, emerge a formulação da prioridade de uma dimensão qualificada por Barbaras como "pulsional" frente à dimensão objetivante da epistemologia clássica da relação sujeito-objeto. Sinalizamos que, para o autor, estes remanejamentos conduzem à necessidade de pensar o corpo, a percepção e o movimento com base na categoria de vida.
\end{abstract}

Palavras-chave: Fenomenologia. Percepção. Corpo. Movimento. Desejo.

10 presente artigo é resultado de projeto de pesquisa apoiado pela FAPESP.

* E-mail para correspondência: danilo.verissimo@gmail.com. 


\section{Introdução}

A percepção é um tema de investigação privilegiado pela tradição fenomenológica. A experiência perceptiva coloca-nos diante do problema de conjugar o que, em primeira instância, refere-se à exterioridade da coisa percebida e à sua singularização mediante um sujeito da percepção. Desde Husserl, passando principalmente por Merleau-Ponty, o problema da percepção sofreu importantes revisões, devidas, sobretudo, à consideração do sujeito da percepção a partir de sua essência corporal. A partir disso, novas questões e novos aportes teóricos vêm sendo desenvolvidos na confluência das noções de corpo, percepção e movimento (Pinto, 2012).É o que se observa na obra de Renaud Barbaras.

Neste artigo, analisamos o trabalho teórico realizado por Barbaras a partir de seu propósito de destacar e desenvolver a potencialidade da teoria husserliana da percepção, fundamentada na doutrina de doação perceptiva por perfis. Centramo-nos principalmente em sua obra intitulada O desejo e a distância: introdução a uma fenomenologia da percepção (Barbaras, 2006), publicada originalmente em 1999. Destacamos a descrição, operada pelo autor, do movimento vital como desejo e a caracterização do sujeito da percepção como vivente. Sinalizamos que, para Barbaras, estes remanejamentos conduzem à necessidade de pensar o corpo, a percepção e o movimento a partir da categoria de vida.

\section{Fenomenologia do aparecer}

A experiência perceptiva nos remete, de pronto, a duas dimensões que lhe são características. Diferentemente da experiência que temos da memória ou da imaginação, a percepção daria acesso ao que se chama comumente de realidade. De fato, ao perceber, não temos a impressão de lidar com a imagem das coisas, com fantasmas. Ao contrário, somos tomados pela conviç̧ão de encontrar uma realidade que já estava lá antes de ser visada por nós. Por outro lado, assim como as lembranças ou os sentimentos, a percepção é minha. Trata-se da "prova que faço da realidade" (Barbaras, 2009, p. 8). Parece um fato incontestável que sem um sujeito da percepção nada apareceria. Daí duas evidências opostas e que coexistem na experiência imediata: "a percepção se faz lá, no mundo, e ela se faz em mim" (Barbaras, 2009, p. 8). A percepção revela as coisas em si mesmas por meio de estados relativos ao sujeito. Na perspectiva da experiência imediata, ingênua, essas constatações não implicam problema algum. A experiência cotidiana é a própria conciliação desses contrários. 
É disso que tratam os versos caeirianos de Fernando Pessoa (2001), que tomamos a liberdade de citar:

Creio no mundo como num malmequer, / Porque o vejo. Mas não penso nele / Porque pensar é não compreender... / O mundo não se fez para pensarmos nele / (Pensar é estar doente dos olhos) / Mas para olharmos para ele e estarmos de acordo. (p. 26)

As incompatibilidades e contradições surgem quando se começa a tentar definir teoricamente a percepção a partir daquelas duas evidências, a do sujeito e a do mundo, numa perspectiva antinômica e marcada por prejuízos teóricos clássicos. Como podem estados subjetivos atingir ou ligar-se a objetos espaciais? O problema da percepção na tradição filosófica é formulado por Barbaras (2009) da seguinte forma:"como posso, a partir de estados subjetivos, imanentes e, portanto, relativos, acessar aquilo que repousa em si mesmo e que é apenas relativo a si mesmo?" (p. 9). É o que em Filosofia se considera como sendo o paradoxo da imanência e da transcendência inscrito na percepção (Merleau-Ponty, 1996).

A partir daí, evolui-se para o que Barbaras (2009) qualifica de "inconsequência grave" (p. 9). Trata-se justamente de definir o sujeito como um conjunto de estados subjetivos, ora constitutivos do mundo percebido, ora constituídos por ele, e a coisa percebida como objeto extenso, determinado pelas propriedades que a Física e a Química imputam às coisas, categorias que não estão implicadas necessariamente na ideia ingênua de que um sujeito une-se a um objeto. À percepção são atribuídas, pois, categorias disponíveis no inventário da Filosofia, como as ordens cartesianas do sujeito racional, vivido, e da coisa extensa. Barbaras (2009) comenta:

A inconsequência consiste aqui em subordinar de antemão a percepção a uma certa acepção da realidade, enquanto que, por definição, é a própria percepção que, na qualidade de acesso originário à realidade, é suscetível de nos liberar o seu sentido. (p. 10, itálicos do autor)

Em outras palavras, o fenômeno que poderia nos revelar o que significa "ser" acaba descrito segundo categorias pré-concebidas de ser que se firmam como hábitos do pensamento. Daí a necessidade de descrever a percepção sem pressupostos, tarefa inseparável da crítica das categorias pelas quais ela foi definida ao longo da tradição filosófica. É o que Merleau-Ponty (1945) busca expressar ao declarar que a "verdadeira filosofia é reaprender a ver o mundo" (p.XVl), afirmação que dispõe a percepção no centro de qualquer preocupação maior de ordem ontológica.

Segundo Barbaras (2006, 2009), a filosofia de Husserl é a primeira a colocar as exigências de uma filosofia da percepção no centro do exercício de seu pensamento. Nos traços de autores como Merleau-Ponty, Mi- 
chel Henry e Patočka, Barbaras esforça-se para identificar e destituir da fenomenologia husserliana os prejuízos herdados da tradição, o que lhe permite tratar, principalmente, da "estrutura do aparecer como tal" (Barbaras, 2006, p. 31, itálico do autor), do fato de que, por meio de qualquer coisa que percebemos, é o próprio aparecer do mundo que se apresenta como tema a partir dos momentos que integram sua unidade.

A estrutura do aparecer é uma questão conquistada por meio da époché fenomenológica. Na atitude ingênua, ou natural, somos fascinados por aquilo que aparece, somos captados por sua presença, de modo que o objeto adquire ares de autossuficiência, e afigura-se apartado de seu aparecer (Barbaras, 2006). Para Husserl (1913/2008), a atitude natural conduz espontaneamente ao naturalismo, à nossa crença na existência de um mundo que repousa em si, na forma de coisa espaço-temporal, determinada por séries causais e dotada de propriedades objetivas. Segundo essa interpretação realista, o momento da aparição, o esboço, ou seja, a perspectiva da coisa percebida que se dá à mostra, é tomado por simples aparência subjetiva, um efeito da coisa real sobre a consciência, que pode, da mesma forma, ser considerada como uma parcela do mundo natural. A époché praticada por Husserl implica a neutralização da tese natural do mundo, não de modo a negar a existência do mundo, mas de modo a, livre da atitude natural, interrogar "o que significa existir para o mundo" (Barbaras, 2009, p. 49). Trata-se, em outras palavras, de romper a fascinação natural que a consciência possui diante do mundo e de "colocar fora de jogo" (Husserl, 1913/2008, p. 99) a validade concedida prontamente à existência espaço-temporal das coisas, "incluindo-se nós mesmos assim como toda espécie de 'cogitare'" (Husserl, 1913/2008, p. 106), desde que concebidos como "eventos naturais do mundo" (Husserl, 1913/2008, p. 107). O que emerge dessa "redução fenomenológica" é a fenomenalidade do mundo, ou seja, o fato de que "o sentido de ser do mundo é ser para uma consciência" (Barbaras, 2009, p. 49). Com isso, não se afirma que a consciência sustentaria sozinha o ser. Pensar assim seria isolar a consciência e fundar o mundo sobre representações de mundo, recriações do aparecer. Dizíamos que o mundo é para uma consciência e não na consciência. Na mesma medida, a própria consciência é para o mundo. Este fato, que, em linhas gerais, é o que Husserl denomina intencionalidade, refere-se à propriedade essencial à consciência de abrir-se a algo distinto dela mesma, de visar alguma coisa. Uma consciência que não visasse nada não seria uma consciência.

Tem-se, pois, fundada a "correlação universal" (Husserl, 1954/2004, p. 172) entre a consciência e o mundo que prescreve aos termos a impossibilidade de preexistirem à relação entre eles. $O$ aparecer, isto é, o ser para uma consciência na qualidade de fenômeno, é uma dimensão constitutiva das coisas. E, de outro lado, o ser do sujeito "não pode ser pensado in- 
dependentemente de sua relação a um ser aparecendo" (Barbaras, 2009, p. 44). A consciência é inteiramente relação às coisas.

\section{Perfis perceptivos}

Baseando-se nos autores citados anteriormente, Barbaras (2006, 2009) identifica em Husserl, não obstante o estabelecimento dessa correlação, um processo de subjetivação da fenomenalidade. Haveria um desnível entre a descrição do campo fenomenal e sua análise calcada naquilo que compõe a percepção. Os desenvolvimentos teóricos propostos por Barbaras em torno da percepção apoiam-se justamente sobre o polo descritivo das teorias husserlianas.

O momento descritivo dos "atos de intuição imediata" (Husserl, 1913/2008, p. 139), ou seja, da percepção, em Husserl, parte da importante constatação de que nos relacionamos com qualquer objeto enquanto identidade única, a despeito do fato de que ele nos é dado"em uma multiplicidade variável e multiforme de aspectos (modos de apresentação)" (Husserl, 1931/2008, p.75). Nada que se apresente a nós de modo originário, quer dizer, "em sua realidade corporal" (Husserl, 1913/2008, p. 78), ou "em carne e osso", deixa de se mostrar sob infindáveis variações. É o que se dá, por exemplo, em relação a minha mesa de trabalho. Deparo com ela a partir de diversas perspectivas, sem que isso empobreça minha consciência de se tratar de uma única e mesma mesa.Em Husserl, este "mistério", longe de clamar por uma solução, é apresentado como a própria "essência da percepção" (Barbaras, 2009, p. 58). A doação do objeto se dá a partir de um complexo sistema de esboços, ou perfis, que dependem das posições de nosso corpo e do uso de nossos sentidos em sua variabilidade incessante. Em primeira instância, trata-se, pois, de descrever o horizonte interno do objeto percebido na relação com o sujeito da percepção.

Esta descrição revela a ambivalência do percebido. A vivência do perfil perceptivo não apresenta o objeto em-si, ou seja, tal como seria em si mesmo, mas sob um ou outro aspecto. De modo que, ao mesmo tempo em que o perfil mostra o próprio objeto, ele o oculta mediante uma aparição parcial."Assim, ao mesmo tempo, o perfil se apaga em proveito do objeto e apaga o objeto em proveito do aspecto sob o qual se apresenta", comenta Barbaras (2009, p. 59). Esta ambivalência equivale à preservação da transcendência do percebido, na medida em que sua apresentação por esboço distingue-se de sua "presença plena": "o objeto se apresenta, mas sempre como outro em relação àquilo que o apresenta" (Barbaras, 2009 , p. 59, itálicos do autor). Dessa forma, o sujeito da percepção não chega a coincidir com o percebido, posto não possuir a chave da integra- 
lidade corpórea do objeto. E este mesmo "recua para trás de sua própria presença" (Barbaras, 2009, p. 59).

Constata-se, portanto, uma dinâmica de conjugação entre presença e ausência, entre visibilidade e invisibilidade, referente à ambiguidade constitutiva que marca o esboço, ou perfil, e o objeto esboçado. Barbaras (2006) faz a seguinte consideração:

Encontramo-nos, pois, em uma estranha situação, dado que a aparição apresenta um objeto que não é outra coisa senão aquilo em que ele se apresenta: a aparição se excede na direção do objeto, mas este excesso não dá lugar a nada além de uma outra aparição. Assim, ela se desfaz em proveito do objeto que, ao mesmo tempo, se desfaz por trás da sua aparição; desvelando o objeto ela o encobre, posto que este jamais é tido como distinto daquilo que o mostra. (p. 23)

O perfil denota, portanto, a identidade entre ele mesmo e aquilo que o ultrapassa, quer dizer, o objeto apresentado. Este, por sua vez, "é dado à consciência em sua corporeidade" (Husserl, 1913/2008, p. 139, itálico do autor), em sua presença efetiva, ao mesmo tempo em que se revela "indefinidamente ausente" (Barbaras, 2006, p. 24). Com efeito, nenhuma série de perfis expõe a"ipseidade corporal" (Husserl, 1913/2008, p. 138) da coisa percebida. Tem-se, por conseguinte, da parte do objeto, a "identidade de uma vinda à presença e de um recuo no inapresentável" (Barbaras, 2006, p. 24). Deste sistema de oposições, depreende-se que tudo aquilo que se apresenta originariamente a nós, ou seja, que se faz presente na percepção, admite uma dimensão de ausência que não pode ser preenchida (Barbaras, 2009).

A doação por perfis é descrita por Husserl como a essência da coisa percebida, o que não deve ser considerado como consequência de uma limitação da subjetividade (Barbaras, 2009). Trata-se, antes, de assumir a tese de uma "distinção fundamental" entre "o ser como vivido" e "o ser como coisa" (Husserl, 1913/2008, p. 135), e suas implicações filosóficas. Segundo Husserl, o vivido da consciência é percebido mediante uma percepção imanente,"sem distância ou profundidade" (Barbaras, 2006, p. 25), e caracterizada pela "identidade do ser e do aparecer" (Barbaras, 2006, p. 26). Já da coisa como tal não se pode ter uma percepção imanente; trata-se, por princípio, de uma transcendência, alcançada nela mesma. A forma como uma e outra se dão são distintas, afirma Husserl.

A coisa é o objeto de nossa percepção enquanto ela "se perfila"... . Um vivido não se dá por perfis. Não é uma propriedade fortuita da coisa ou um acaso da "nossa constituição humana" que "nossa" percepção não possa alcançar as coisas elas mesmas senão por intermédio de simples perfis. Encontramo-nos, ao contrário, no plano da evidência: a essência mesma da coisa espacial ... ensinanos que este tipo não pode, por princípio, ser dado à percepção senão por perfis. (Husserl,1913/2008, p. 136, itálicos do autor) 
O objeto percebido apenas "aparece" sob determinada "orientação", "cada uma envolvendo novas orientações cuja possibilidade é sistematicamente prefigurada na precedente" (Husserl, 1913/2008, p.136), de modo que nos exprimimos dizendo que um ou outro lado da coisa se dá.

O que gostaríamos de destacar aqui é a determinação de que a percepção atinge a coisa mesma. Esta afirmação possui uma implicação dupla. Primeiro, que os perfis não são aparências relativas à presença do objeto. Se se tratasse de aparências, seríamos reenviados à ideia de que a percepção nos daria imagens ou signos da coisa, cuja presença seria apenas indicada (Husserl, 1913/2008). Em segundo lugar, atesta-se que a presença da coisa mesma não se refere à coisa em si mesma, como totalidade apresentada diretamente, sem nenhuma opacidade. Se assim fosse, estaríamos diante da ambição de se ter acesso à ipseidade do percebido, tipo de intuição que, Husserl lembra bem, normalmente se atribui a um deus, que teria consciência da coisa como de um vivido de sua própria consciência. Voltemo-nos mais uma vez às palavras do filósofo:

A percepção de uma coisa não presentifica o que não está presente, como se a percepção fosse uma lembrança ou uma imagem; ela apresenta, ela toca a coisa mesma em sua presença corporal, e isso em virtude do seu sentido próprio: violentaríamos seu sentido se supuséssemos outra coisa a seu respeito.Se, como se faz aqui, visa-se, sobretudo, a percepção das coisas, sua essência implica que ela seja uma percepção que procede por perfis; correlativamente, o sentido do seu objeto intencional, quer dizer, da coisa na qualidade de dada na percepção, implica, por princípio, que apenas seja perceptível por meio de percepções desta sorte, ou seja, procedendo por perfis. (Husserl, 1913/2008, p. 140, itálicos do autor)

Barbaras $(2006,2009)$ salienta o valor das formulações husserlianas como crítica à tradição das filosofias da percepção identificadas com a diferenciação entre a coisa e suas aparências, e com o reconhecimento implícito da possibilidade, se não de fato, ao menos de direito, de um acesso direto à coisa, independente dos perfis perceptivos. Nessa direção, ao perfil seria outorgada a qualidade daquilo que "compromete o acesso à coisa mesma" (Barbaras, 2006, p. 26). Vimos que, em Husserl, "o perfil dá acesso à coisa mesma e não à sua imagem" (Barbaras, 2006, p. 26). A percepção é tomada como doação da coisa percebida "em carne e osso", distinguindo-se, portanto, as aparições, ou seja, os modos de doação da coisa, de meras aparências. "O perfil não é a coisa, mas ele não é uma aparência, dado que é a coisa mesma que ele perfila", comenta Barbaras (2006, p. 26). A questão que se apresenta é, pois, a de pensar o lugar da aparição, que, se não é aparência, também não coincide com a coisa mesma, "da qual ela é apenas a aparição" (p. 26). O fato é que, contra o arcabouço teórico empirista, o perfil perceptivo opõe-se à ideia de "conteúdos sensíveis fechados" (p. 27), ou isolados. O perfil não compõe 
o objeto, mas o manifesta encarnando sua forma. Contra o imaginário intelectualista, o acesso à coisa mesma se dá mediante os perfis sensíveis. Não se afirma que temos acesso à imagem ou às propriedades geométricas da coisa, nem tampouco seus momentos sensíveis são degradados a simples aparências.

De acordo com Barbaras (2006), em Husserl a descrição da percepção como doação por perfis se faz em proveito do momento analítico de determinação dos estados de consciência, dos vividos puros. Husserl (1913/2008) distingue dois tipos de vividos: a hylé sensual (matéria) e a morphé (forma), ou vivido noético (noese). O primeiro seria um puro dado de sensação e corresponderia ao momento de receptividade por parte da consciência. O segundo animaria os dados hyléticos, apreendendo-os em função de um sentido, constituindo-os como aparição de algo, de maneira que a hylé torna-se esboço de um momento do objeto a partir da noese. Aqui, o perfil perceptivo e seus horizontes não são anotados como momentos da estrutura do próprio aparecer, mas antes como resultado de um ato subjetivo de doação de sentido. Com efeito, em Meditações cartesianas, Husserl (1931/2001) afirma:"Cada estado de consciência possui um 'horizonte'" (p. 82, itálicos nossos), e, em Ideias I, atrela o horizonte percebido ao "campo total de noeses potenciais". Nestes termos, o exterior parece ser reintegrado à imanência na qualidade de unidade de sentido sustentada pela atividade de síntese dos vividos por parte da consciência, o que anula a distância que caracteriza a doação do mundo por perfis (Ramos, 2012).

Daí Merleau-Ponty (2011) argumentar que, em Husserl, a abertura, ao ser promovida pela síntese perceptiva, permanece como abertura a um valor, a um significado, o que "implica concepção do sentido como essência" (Merleau-Ponty, 2011, p.48, itálicos do autor).Com isso, Merleau-Ponty busca afirmar que a síntese perceptiva, assim concebida, mantém-nos numa espécie de intelectualismo. Nessa direção, Michel Henry (1988/2005) afirma categoricamente: "Husserl diz que o objeto é um polo de identidade ideal além da multiplicidade de suas aparições sensíveis" (p.31).

Para Barbaras (2006), na esteira dos autores dos quais ele se serve, a crítica à subjetivação do sistema de horizontes aproxima a intuição fundamental de Husserl da caracterização da estrutura do aparecer. A esta estrutura caberá o papel de servir como o fio para a caracterização do sujeito do aparecer, de modo que se concede ao campo fenomenal, e não mais ao vivido, o caráter de dado fenomenológico primordial. $\mathrm{O}$ aparecer do mundo revela, então, uma correlação inextricável entre aquilo que aparece, o para o que ele aparece e o como ele aparece, segundo a fórmula que Barbaras encontra em Patočka (1995). O aparecer de algo apenas pode ser concebido na relação com um sujeito da percepção, aquele para quem o que aparece se manifesta. Este fato representa a natureza fenomenal do mundo. Por outro lado, aquele para quem alguma 
coisa aparece deve ser tratado primordialmente em função daquilo em relação ao que ele se revela como ser de abertura. Conforme Patočka, ainda que se objete que a estrutura do aparecer do mundo encontra no sujeito seu fundamento, sua condição de ser, trata-se de um sujeito que não aparece como um eu, ou como algo de natureza egoica, mas como subjetividade "que antes se manifesta 'nas' próprias coisas e em concerto com elas" (Patočka, 1995, p. 171). O sujeito não ocupa, aqui, o lugar daquele que cria a aparição, mas o de momento da constituição da estrutura do aparecer do mundo, que apenas existe no modo de "aparecer para" (Barbaras, 2006, p. 89, grifo do autor). É no interior desta condição que a questão sobre o modo de ser daquele que percebe, o sujeito perceptivo, será tratada. Opera-se uma inversão na qual a consciência se dá como "subordinada à aparição do mundo" (Barbaras, 2006, p. 88). Nas palavras de Patočka (1995), trata-se não de pensar "o aparecer enquanto tal como qualquer coisa subjetiva, mas ao contrário o subjetivo como 'realização' da estrutura da aparição" (p. 197). Quanto ao como do aparecer, somos endereçados justamente ao reconhecimento de que a coisa percebida se dá por perfis, numa dinâmica que conjuga presença e ausência de modo essencial. Além desse horizonte interno, relativo ao objeto percebido, é preciso considerar que tudo o que aparece sempre o faz em meio a outra coisa. De modo que à estrutura de horizontes internos corresponde um horizonte externo. A aparição se dá no interior de um campo, que, da mesma forma como o objeto percebido, não aparece completamente, senão como fundo sempre pronto a abrir novos planos. Nestes termos, a estrutura do aparecer apresenta, em suma, um modo de ser original,"que desafia o princípio de identidade", comenta Barbaras (2006, p. 100).

A propósito deste ser original, é oportuno invocar Merleau-Ponty (1964/2006), que fala do mundo sensível, do mundo transcendente, como mundo de horizonte. O filósofo discute a relação entre o visível e o invisível, definindo este último não apenas como o não visível, mas como ausência que conta no mundo, o negativo,"a lacuna que marca seu lugar em um dos pontos de passagem do 'mundo'"' (Merleau-Ponty, 1964/2006, p. 277), de modo que os visíveis encontram-se centrados nos núcleos de ausência, e que a transcendência da coisa percebida passa a ser definida como "identidade na diferença" (Merleau-Ponty, 1964/2006, p. 274). Recorrendo à noção de forma, jamais abandonada por ele, Merleau-Ponty define a Gestalt, representada, por exemplo, num contorno, ou num processo de segregação figural, não como algo ancorado num ponto definido do espaço e tempo objetivos, nem tampouco como não-espacial ou atemporal, mas como uma região "onde ela está presente por toda parte sem que se possa jamais dizer:é aqui" (Merleau-Ponty, 1964/2006, p. 255). O percebido define-se nas vicissitudes da própria estrutura figura-fundo, de modo que o campo, ou fundo da aparição, está implicado na estrutura do aparecer. 
No que diz respeito a esta estrutura, pode-se afirmar que o fundo do aparecer daquilo que aparece é, em última instância, justamente o mundo, tomado como "a totalidade das coisas perceptíveis e a coisa de todas as coisas" (Merleau-Ponty, 1996, p. 50), ou como este "omni-englobante ser único", que "deve estar sempre aqui como plano de fundo permanente da experiência" (Patočka, 1995, p. 214, itálico do autor). Trata-se, pois, de definir a totalidade que coaparece em todo aparecer. Barbaras (2006) escreve:

Como unidade originária de um dado e de uma condição de doação, o mundo é a identidade da forma e do conteúdo, ou melhor, sua indiferença.... ele não pode ser assimilado a uma forma, posto que, ao contrário, ele é o aparecendo último: ele corresponde àquilo que, em cada aparição, não aparece, a dimensão inapresentável e inesgotável de cada apresentação. (p. 85)

Mais adiante em seu texto, o autor comenta:"toda aparição é coaparição do mundo, todo aparecendo destaca-se de uma totalidade não totalizável onde ele se inscreve" (Barbaras, 2006, p. 129). O mundo não pode ser sobrevoado justamente porque ele se mostra como totalidade omni-englobante. As aparições são correlativas à "inapresentabilidade do mundo" (Barbaras, 2006, p. 130). Trata-se, portanto, não de defini-lo como objeto no sentido da Física, submetido a uma única lei de constituição e considerado a partir de lugar nenhum, mas de atentar para a sua "presença inalienável" (Merleau-Ponty, 1945, p. I), para o mundo que "já está sempre 'ali', antes da reflexão" (p.l).

\section{O movimento vital como desejo}

Até aqui foi preciso fixar os pontos centrais do estudo acerca da estrutura do aparecer. Podemos, doravante, dedicarmo-nos às principais consequências dessa fenomenologia, que leva Barbaras (2006) à proposição do movimento vital como desejo e, mais ainda, à consideração do modo de existir do sujeito vivo como desejo.

A fidelidade à estrutura do aparecer e, portanto, à inapresentabilidade do mundo, essência do aparecer, implica considerar que estamos sempre num ponto do mundo. Isso significa que fazemos parte dele, que também somos algo visível, cuja apresentação para si mesmo e para qualquer outro percipiente se dá por perfis. Em virtude disso, Patočka (1995) dirige-se à experiência como"uma trama estendida entre dois horizontes", um deles relativo ao nosso próprio eu encarnado. Esta é nossa dimensão de proximidade com o mundo. Mas para que haja o aparecer, a proximidade precisa articular-se com a distância. Minha visibilidade é 
acessível a ela mesma e se destina à visibilidade do mundo, que é profunda, posto que o vejo do ponto onde estou. É preciso adentrar o mundo, sua profundidade. $O$ que jamais me retira de um determinado lugar. "O olhar não vence a profundidade, ele a contorna", diz Merleau-Ponty (1964/2006, p. 268). Daí a dupla implicação de nossa inscrição no mundo na qualidade de seres encarnados: estamos no mundo, o que quer dizer que partilhamos com ele o aparecer em profundidade; e somos capazes de percorrer as infinitas faces do mundo, de explorar sua profundidade, posto que, como sentientes, não coincidimos com ele.

Passamos, pois, a tratar do modo de ser específico do sujeito da estrutura do aparecer. Ele não coincide com o mundo. Sua proximidade com as coisas, sua participação à "massa do sensível" (Merleau-Ponty, 1964/2006, p. 177) se dá em coordenação com seu caráter de sentiente, fato que faz parte da possibilidade da estrutura do aparecer. Barbaras (2006) comenta:

Se o sujeito está situado no seio do mundo, ele existe, contudo, de modo bem diferente daquele dos outros seres mundanos: enquanto mediador do aparecer, ele está adaptado à sua estrutura, ele existe de tal forma que, por ele, a presença da inapresentabilidade do mundo no seio do horizonte torna-se possível.(p. 107)

Para Barbaras (2006), o problema da compreensão do sentido de ser do sujeito reside justamente na dificuldade para conciliar o fato de que não existimos como os outros seres mundanos e, ao mesmo tempo, possuímos um parentesco ontológico com o mundo. Vimos que definir o sujeito a partir da teoria do vivido nos leva à subjetivação do aparecer. Sob essa condição, mesmo se tratando de um sujeito encarnado, não se deixaria de atualizar o dualismo psicofísico a partir da definição de uma dimensão qualquer em que o sujeito repousaria sobre si mesmo. $\mathrm{E}, \mathrm{em}$ última instância, não se vê como um sujeito que repousa sobre si mesmo poderia voltar-se aos objetos. Para compreendermos nossa "enigmática aptidão para entrar no mundo como impresentável" (Umbelino, 2009, p. 152 , itálico do autor), cumpre estender ao sujeito a negatividade própria ao horizonte da percepção. O não-ser do horizonte da percepção possui o status de "excesso de toda aparição sobre ela mesma" (Barbaras, 2006, pp. 107-108). A aparição se dá, ao mesmo tempo, como negação e manifestação de uma totalidade que não pode ser positivamente exibida. Se, no interior da estrutura do aparecer, a coisa percebida não coincide consigo mesma, ao horizonte "não pode corresponder senão um sujeito que é seu próprio excesso", escreve Barbaras (2006, p. 108). A negatividade interior ao mundo deve ser a outra face da negatividade constitutiva do próprio sujeito-para-o-horizonte, a incompletude do mundo o outro ângulo do caráter provisório da identidade do sujeito. 
A hipótese de Barbaras (2006) é que o sentido primordial dessa negatividade pode ser encontrado na mobilidade. Voltemos ao problema da profundidade do percebido. Merleau-Ponty (1945) fala da originalidade da profundidade, a "mais existencial" (p. 296) das dimensões. Na perspectiva do mundo e do espaço objetivos, de onde falam o intelectualismo e o empirismo, a percepção da profundidade é assimilada à largura das coisas consideradas de perfil. Tudo se passa como se devêssemos nos colocar na posição ubíqua de um ser divino, capaz de situar-se lateralmente diante das coisas. Ou ainda, como se se tratasse de considerar as coisas por elas mesmas, retirando de jogo a implicação entre o sujeito perceptivo e as coisas. O mundo, todavia, não se encontra ao redor de nós como um sistema de objetos exteriores uns aos outros, "mas como um conjunto aberto de coisas para as quais nos projetamos" (Merleau-Ponty, 1945, p. 444). Um dos elementos essenciais do espaço vivido, este que se encontra aquém dos prejuízos de um mundo objetivo, e que se revela, ou se abre, na estrutura de horizontes, é o movimento. Enquanto nosso corpo move a si próprio, ele se mostra "inseparável de uma vista do mundo" (p.445) organizada em torno de sua potência de movimento, ou seja, da infinidade de horizontes que brotam do "eu posso" que caracteriza nossa corporeidade. Nessa direção, Barbaras (2006) fala da negatividade concreta expressa no movimento."Mover-se é não ser o que se é (ou era), é estar sempre além e, portanto, aquém de si mesmo, é existir sobre o modo da não-coincidência", afirma o autor (Barbaras, 2006, p. 108). Para ele, o movimento é, pois, a dimensão do corpo que estabelece uma relação constitutiva em relação à negatividade que caracteriza a experiência perceptiva, com seus objetos abertos e inacabados. Barbaras (2006) comenta: "é enquanto sujeito capaz de movimento que o sujeito perceptivo poderá ser tocado em seu ser verdadeiro" (p. 108). O movimento, a título de contrapartida, reflui "para uma forma de interioridade" (Barbaras, 2006, p. 116), caracterizada pelo excesso de sua potência sobre seus atos. A cada movimento restaura-se a exigência de continuação, posto que, do lado do percebido, o movimento se coloca sempre aquém daquilo que visa, e, do lado do próprio percipiente, cada "eu faço" se refere a uma dimensão de excesso do "eu posso".

Barbaras (2006) resume este circuito do aparecer com as seguintes palavras:"não há existência exterior senão comportando uma nova profundidade" (p. 118). Isso quer dizer que a impercepção, subentendida em cada apresentação do mundo, reclama o movimento, que este se constitui como atividade perfeitamente acoplada ao momento de passividade $^{2}$. Trata-se, pois, de afirmar a unidade entre percepção e movimento. Nenhuma percepção é capaz de extinguir a tensão constitutiva do mo-

2 Umbelino (2009) afirma: “0 movimento é, de facto, a medida de um eu posso não impositivo, de uma actividade que não é contrária à passividade; e, neste sentido, é justa capacidade de correspondência por aproximação a uma realidade cuja visibilidade é transida de uma invisibilidade sustentadora" (p. 152, itálico do autor). 
vimento e, nessa medida, toda percepção está fadada a dar lugar à outra percepção (Barbaras, 2006).

Essa ordem de ausência que se revela na percepção e no movimento como característica do sujeito do aparecer aproxima-nos de uma dinâmica pulsional que Barbaras (2006) trata como originária em relação aos fenômenos perceptivo e motor. O "movimento fundamental" do sujeito vivo será, então, definido pelo filósofo como desejo, dispositivo central para se descrever o próprio fenômeno da vida como negatividade e para nela enraizar o sentido da transcendência. Barbaras (2006) se expressa da seguinte forma:"Ao horizonte, como apresentação do inapresentável, não pode responder senão o desejo, na medida em que seu 'objeto' apenas se dá a ele sobre o modo da falta e, portanto, reclama sempre uma nova satisfação" (p. 136).

Barbaras (2006) apressa-se em diferenciar o desejo da necessidade. Ao contrário do que se passa na condição de necessidade, dirigida por uma falta definida, passível de ser preenchida pelo objeto que a satisfaz, ao desejo não falta nada, no sentido de que "nada pode preenchê-lo" (Barbaras, 2006, p. 136, itálicos do autor). Trata-se de uma "insatisfação absoluta"','falta originária", de modo que seria preciso inverter a ordem tradicional de dependência entre desejo e necessidade. Aquele não responde por uma aspiração mais elevada e facultativa, ou por uma sublimação, em relação ao caráter indispensável e essencial da satisfação das necessidades. Ao contrário, estas é que "seriam uma manifestação da vida como pura aspiração, não coincidência originária" (Barbaras, 2006, p. 137). No que diz respeito ao transcendente, vale reforçar que o desejo como falta essencial implica um objeto que se encontra sempre aquém de si mesmo, de maneira que "a presença correlativa do desejo é ao mesmo tempo ausência de presença", comenta Barbaras (2006, p. 137). Mais adiante o autor afirma:"o objeto do desejo é aquele que jamais pode estar presente como tal" (Barbaras, 2006, p. 138).

A identificação do sujeito do aparecer à pulsão, ao desejo, passa pela sua caracterização como vivente. É o modo de existir do vivente que será caracterizado como desejo e não uma consciência que constituiria o percebido a partir de seus vividos. Neste exercício, Barbaras (2006) faz eco à opção de Merleau-Ponty (1942/1967), desde seu primeiro trabalho, A estrutura do comportamento, de integrar à fenomenologia o organicismo estruturalista representado, entre outros autores, por Kurt Goldstein. Seu objetivo: inscrever "a experiência perceptiva na existência vital que caracteriza o percipiente" (Barbaras, 2006, pp. 144-145).

Goldstein (1934/1983) assume a existência do vivente como totalidade. O autor mostra, por exemplo, que qualquer processo de estimulação do organismo será processado não por aparelhos orgânicos isolados, mas pelo todo orgânico, razão pela qual estímulos idênticos podem agir de maneiras distintas, a depender do estado do sistema orgânico num 
dado momento. O organismo é tomado como estrutura, na qual acontecimentos particulares não adquirem sentido senão a partir do funcionamento sistêmico, sendo o funcionamento isolado característica de quadros patológicos. Ao organismo como forma corresponde uma estrutura mais ampla e fundamental: a composição entre o organismo e o meio ambiente. Goldstein refere-se ao "debate" entre o organismo e o meio, bem como ao fato de que a "natureza" do organismo atualiza-se a partir das mudanças no ambiente que o estimulam, de maneira que as exigências do meio configuram-se como ocasião para a realização da singularidade orgânica. Conforme Barbaras (2006), trata-se de observar um processo circular em que o meio, tomado como conjunto ao qual o organismo será sensível, constitui-se a partir de normas próprias ao conjunto orgânico. O filósofo comenta:

Vê-se que o vivente forma com seu meio uma totalidade em que é impossível, de direito, distinguir o que cabe propriamente ao organismo e o que provém do exterior, discernir uma dimensão de passividade que já não seria atravessada por atividade. (Barbaras, 2006, p. 143)

Isto posto, resta pensar o caráter de tensão presente na estrutura organismo-meio. Ainda é a Goldstein que Barbaras recorre, na medida em que o primeiro trata a criatura particular como imperfeição no tocante à totalidade do ser. A estrutura organismo-meio difere da "Totalidade originária", da "calma continuidade com o Todo". A individualidade orgânica é ruidosa na medida em que implica separação em relação à totalidade originária, uma privação de ser, que reserva ao vivente a tarefa de existir "como aquilo cuja essência permanece irrealizável" (Barbaras, 2006, p. 146), a não ser pelo seu "desaparecimento por dissolução na totalidade" (p. 146). O autor comenta:

Tal é sem dúvida a diferença entre o vivente e os outros corpos:estes permanecem na calma continuidade com o Todo, enquanto o vivente, fazendo-se ele mesmo totalidade, não pode se reportar à Totalidade originária senão sob o modo de ausência. (Barbaras, 2006, p. 146)

A instituição do vivente implica a alienação do mundo, de maneira que a continuidade torna-se tensão, que se configura na dimensão de relação do vivente com o mundo e estabelece o "ser fenomenal do mundo". Voltamos à relação entre presença e ausência, visibilidade e invisibilidade, na medida em que, em última instância, é ao mundo como "englobante originário","'totalidade", que o vivente se endereça, sem encontrá-lo jamais como tal. A totalidade se apresenta como o inapresentável, que aparece apenas naquilo que a nega, na relação entre a individualidade do vivente e seu próprio mundo. Em outras palavras, comenta Barbaras 
(2006), a totalidade não tem realidade fora de seus momentos finitos, tal como a experiência singular, que, ao negar o Todo do mundo, revela-se, ao mesmo tempo, como sua manifestação.

Segue-se a estas considerações a retomada da relação entre percepção, movimento e a caracterização do vivente como desejo. $O$ desejo coincide com o"sujeito de horizonte",imerso na lógica de deparar-se com a totalidade mediante aquilo que a limita. É porque o sujeito é sujeito do desejo que ele é capaz de percepção, afirma Barbaras (2006). Sua atividade funda-se no desdobramento do todo mediante a imagem, ou o percebido, que o nega. O filósofo comenta:"enquanto não há percepção senão como limitação de uma totalidade que ela indica, toda percepção reclama, por essência, sua ultrapassagem e, portanto, dá lugar necessariamente a um movimento" (Barbaras, 2006, p. 151). Percepção e movimento "passam um no outro" (p. 151), escreve ainda, constituindo "expressões abstratas de um Movimento fundamental" (p. 151).

\section{À guisa de conclusão}

A reflexão colocada em marcha por Barbaras (2006) parte da renúncia a uma consciência que constitua o percebido com base em conteúdos de sensação. Em Husserl, esta perspectiva a ser ultrapassada convive com sua "descoberta maior" (Barbaras, 2006, p. 152): a doação por perfis. Barbaras impõe-se a tarefa de "dar sentido" à doação por perfis, exercício que, segundo o autor, nos mantém em consonância com a exigência maior de "pensar segundo a percepção" (p. 59), em contato com o aparecer.

Desse método emerge a formulação da prioridade de uma dimensão qualificada por Barbaras (2006) como "pulsional" frente à dimensão objetivante da epistemologia clássica da relação sujeito-objeto. A filosofia francesa do pós-guerra, bem representada na figura de Merleau-Ponty, já delineava resultados nessa direção, sobretudo a partir da influência da psicanálise. Merleau-Ponty (1994) afirma, por exemplo, que "a percepção [é] um modo de desejo, uma relação de ser e não de conhecimento" (p. 272). Segundo Barbaras, a arqueologia dessa forma de compreensão deve revelar que a obra do próprio Husserl já é perpassada pelo estudo da pulsão, sobretudo no quadro de análises genéticas conduzidas pelo filósofo e que, diferentemente de análises estáticas, visam a "própria origem das formações de sentido transcendentalmente constituídos" (Barbaras, 2006, p. 137).

Vimos que assumir o desejo como condição de possibilidade da percepção implica que o motivo fenomenológico dos horizontes perceptivos seja transportado para uma rede conceitual em que o sujeito da percepção é um ser vivo e não uma consciência. $O$ sujeito da experiência, 
enquanto sujeito de horizonte, relaciona-se a uma totalidade originária que se ausenta sempre, de modo que a percepção passa a figurar como "determinação-negação da totalidade do mundo" (Barbaras, 2006, p. 150), ou seja, como desejo. A vida é a manifestação empírica do desejo, que não possui realidade senão na exploração do mundo por parte do sujeito.

Em trabalhos posteriores, Barbaras $(2003,2008,2011)$ concentra seus esforços na delimitação do que ele próprio chama de fenomenologia da vida. O estado atual desta área ainda exige a confrontação com temas pautados em termos da ontologia clássica: como pensar a cooriginalidade da vida e da consciência? Quais as condições para que essa identidade possa ser verdadeiramente concebida? Nos termos de Barbaras (2008), "Em qual sentido do viver a vida é necessariamente 'consciência', e a consciência necessariamente viva?" (p. 21).

Vale considerar que o status filosófico da vida constitui um problema central para as ciências humanas, condicionando seu equilíbrio em meio às dicotomias clássicas do pensamento ocidental. No que diz respeito à psicologia, Barbaras (2006) sinaliza a possibilidade de renovação das teorias da dualidade psicofísica e do inconsciente a partir da definição do sujeito como desejo. A unidade dinâmica da vida não aboliria a dualidade entre corpo e alma? Quanto ao inconsciente, não corresponderia ele à totalidade não totalizável do mundo, e, portanto, não estaria ele antes "diante de nós" do que "em nós"?

The pulsion dimension of the sensitive: Elaborations about perception in Renaud Barbaras

\begin{abstract}
In this paper, we analyze the theoretical work of Renaud Barbaras, departing from his proposal to highlight and develop the potential of Husserl's theory of perception, based on the doctrine of perceptive donation according to profiles. We mainly focused on his work entitled Desire and distance: introduction to a phenomenology of perception. We underline the description, operated by the author, about the vital movement as desire and the characterization of the subject of the perception as living. In this condition, the formulation about the priority of a dimension emerges, qualified by Barbaras as pulsion towards the objectifying dimension of classical epistemology in the subject-object relation. We indicate that, according to the author, these rearrangements entail the need to consider the body, perception and movement based on the category of life.
\end{abstract}

Keywords: Phenomenology. Perception. Body. Movement. Desire. 


\section{La dimensión pulsional del sensible: elaboraciones sobre la percepción en Renaud Barbaras}

Resumen: En este artículo, analizamos el trabajo teórico de Renaud Barbaras, a partir de su propósito de destacar y desarrollar la potencialidad de la teoría Husserliana de la percepción, fundamentada en la doctrina de la donación perceptiva por perfiles. Nos centramos principalmente en su obra intitulada El deseo y la distancia: introducción a una fenomenología de la percepción. Destacamos la descripción, operada por el autor, del movimiento vital como deseo y la caracterización del sujeto de la percepción como viviente. Bajo esta condición emerge la formulación de la prioridad de una dimensión cualificada por Barbaras como pulsional ante la dimensión objetivante de la epistemología clásica de la relación sujeto-objeto. Señalamos que, para el autor, estas modificaciones llevan a la necesidad de pensar el cuerpo, la percepción y el movimiento a partir de la categoría de vida.

Palabras-clave: Fenomenologia. Percepción. Cuerpo. Movimento. Deseo.

\section{La dimension pulsionnelle du sensible: elaborations sur la perception chez Renaud Barbaras}

Résumé: Dans cet article, nous faisons l'analyse du travail théorique réalisé par Renaud Barbaras dont l'objectif est de mettre en évidence et de développer la potentialité de la théorie husserlienne de la perception, fondée sur la doctrine de donation par esquisses perceptives. Nous nous centrons principalement sur son ouvrage intitulé Le désir et la distance: introduction à une phénoménologie de la perception. Nous soulignons la description, accomplie par l'auteur, du mouvement vital comme désir et la caractérisation du sujet de la perception comme sujet vivant. Sous cette condition, émerge la formulation de la priorité d'une dimension que Barbaras qualifie de pulsionnelle en regard de la dimension objectivante de la relation sujet-objet admise par l'épistémologie classique. Nous signalons que, selon l'auteur, ces remaniements conduisent à la nécessité de penser le corps, la perception et le mouvement selon la catégorie de vie.

Mots-clés: Phénoménologie. Perception. Corps. Mouvement. Désir. 


\section{Referências}

Barbaras, R. (2003). Vie et intentionnalité: recherches phénoménologiques. Paris: Vrin.

Barbaras, R. (2006). Le désir et la distance: introduction à une phénoméologie de la perception (2a ed.). Paris: Vrin.

Barbaras, R. (2008). Introduction à une phénoménologie de la vie. Paris: Vrin.

Barbaras, R. (2009). La perception: essai sur le sensible (2a ed.). Paris: Vrin.

Barbaras, R. (2011). La vie lacunaire. Paris: Vrin.

Goldstein, K. (1983). La structure de l'organisme: introduction à la biologie à partir de la pathologie humaine (E. Burckhardt \& J. Kuntz, trads.) Paris: Gallimard. (Trabalho original publicado em 1934)

Henry, M. (2005). Voir l'invisible: sur Kandinsky. Paris: PUF. (Trabalho original publicado em 1988)

Husserl, E. (2001). Méditations cartésiennes: introduction à la phénoménologie. Paris: Vrin. (Trabalho original publicado em 1931)

Husserl, E. (2004). La crise des sciences européennes et la phénoménologie transcendantale (G. Granel, trad.). Paris: Gallimard. (Trabalho original publicado em 1954)

Husserl, E. (2008). Idées directrices pour une phénoménologie et une philosophie phénoménologique pures (P. Ricoeur, trad.). Paris: Gallimard. (Trabalho original publicado em 1913)

Merleau-Ponty, M. (1945). Phénoménologie de la perception. Paris: Gallimard.

Merleau-Ponty, M. (1967). La structure du comportement. Paris: PUF. (Trabalho original publicado em 1942)

Merleau-Ponty, M. (1994). La nature: cours du Collège de France: notes, suivi des résumés de cours correspondants. Paris: Seuil.

Merleau-Ponty, M. (1996). Le primat de la perception et ses conséquences philosophiques. Lagrasse: Verier.

Merleau-Ponty, M. (2006). Le visible et l'invisible. Paris: Gallimard. (Trabalho original publicado em 1964) 
Merleau-Ponty, M. (2011). Le monde sensible et le monde de l'expression: cours au Collège de France, notes, 1953. Genève: Metispresses.

Patočka, J. (1995). Papiers phénoménologiques (E. Abrans, trad.). Grenoble: Millon.

Pessoa, F. (2001). Poesia: Alberto Caeiro. São Paulo: Companhia das Letras.

Pinto, D. (2012). A vida entre desejo e criação: Renaud Barbaras, leitor crítico de Bergson. Cadernos Espinosanos, 27, 31-61.

Ramos, S. (2012). A experiência da falta e o mistério do desejo. Cadernos Espinosanos, $27,159-178$.

Umbelino, L. (2009). Percepção e desejo. Leituras de R. Barbaras. Revista Filosófica de Coimbra, 35, 135-160.

Recebido: 03/5/2013

Aceito: 29/09/2013 